\title{
Performance of Lithium Ion Cell Anode Graphites Under Various Cycling Conditions
}

\author{
Paul Ridgway ${ }^{1}$, Honghe Zheng ${ }^{1}$, Gao Liu ${ }^{1}$, Xiangun Song ${ }^{1}$, Abdelbast Guerfi ${ }^{2}$, \\ Patrick Charest $^{2}$, Karim Zaghib ${ }^{2}$, Vincent Battaglia ${ }^{1}$ \\ ${ }^{1}$ Lawrence Berkeley National Laboratory, MS70-108B, 1 Cyclotron Rd., Berkeley, CA 94720 \\ ${ }^{2}$ Institut de Recherche d'Hydro-Québec, 1800 Lionel Boulet, Varennes, QC, Canada, J3X 1S1
}

Graphites MCMB-2810 and OMAC-15 (made by Osaka Gas Inc.), and SNG12 (Hydro Québec, Inc.) were evaluated (in coin cells with lithium counter electrodes) as anode materials for lithium-ion cells intended for use in hybrid electric vehicles. Though the reversible capacity obtained for SNG was slightly higher than that of OMAC or MCMB, its $1^{\text {st }}$ cycle efficiency was lower.

Voltage vs capacity plots of cycling data show that the discharge and charge limits shift to higher capacity values due to continuation of anode side reactions. Varying the cycle charge and discharge limits was found to have no significant effect on fractional capacity shift per cycle.

\section{Introduction}

Carbonaceous materials, graphite formulations in particular, are the current standard for lithium-ion anodes for electric vehicle batteries(1). Until recently, Osaka Gas product MCMB was considered by many to be the industry standard for this application. As this material is no longer produced, an acceptable alternative is needed. In this work two graphite materials are evaluated along with MCMB in "lithium half-cells" (cells with lithium counter electrodes) by comparing their reversible capacities and first cycle efficiencies.

Another aspect of anode performance is the effectiveness of the Solid-Electrolyte Interphase (SEI) layer in inhibiting the side reactions which form it. The continuation of these side reactions reduces cycling efficiency and consumes electrolyte which reduces the lifetime of the cell. We compare the extent of these continuing side reactions in the three materials by measuring the "fractional capacity shift" as explained in the Results section.

In comparing the performance of the three anodes, the cells were cycled between a cell charge (anode lithiation) limit of $5 \mathrm{mV}$ and a discharge (delithiation) limit of 1V. Use of these or similar limits is convenient but are not the cycle limits experienced by anodes in commercial cells. Therefore, we also measured the capacity shift under cycle limits modified to simulate those to which the anode is more likely subjected in a commercial cell. 


\section{Experimental}

Characterization of anode materials and laminates

Samples of MCMB-2810, SNG-12 and OMAC-15 were provided by Hydro Québec, Inc (HQ). in the form of pure powders and electrode laminates. The powders were subjected to particle size and BET surface area analysis. The results are shown in Table I. Though the particle sizes are very similar, the BET surface area of SNG is about four times greater than that of the other two, indicating a much more open or porous particle structure.

Table I. Results of particle size and BET surface area analyses of the three carbons.

\begin{tabular}{|l|l|l|}
\hline & PSA & BET \\
\hline SNG-12 & $\begin{array}{l}\mathrm{d}-50: \\
12.10 \mu \mathrm{m}\end{array}$ & $\begin{array}{l}\text { Surface area: } 8.59 \mathrm{~m}^{2} / \mathrm{g} \\
\text { Average particle size: } \\
\text { (calc.) } 0.3 \mu \mathrm{m}\end{array}$ \\
\hline OMAC-15 & $\mathrm{d}-50:$ & $\begin{array}{l}\text { Surface area: } 2.59 \mathrm{~m}^{2} / \mathrm{g} \\
\text { Average particle size: } \\
\text { (calc.) } 1.105 \mu \mathrm{m}\end{array}$ \\
\hline $\begin{array}{l}\text { MCMB- } \\
1028\end{array}$ & $\begin{array}{l}\mathrm{d}-50: \\
12.13 \mu \mathrm{m}\end{array}$ & $\begin{array}{l}\text { Surface area: } 1.96 \mathrm{~m}^{2} / \mathrm{g} \\
\text { Average particle size: } \\
\text { (calc.) } 1.5 \mu \mathrm{m}\end{array}$ \\
\hline
\end{tabular}

In the SEM images of the powders and HQ's laminates in Figures 1 and 2, SNG and OMAC look similar. The larger BET surface area of the SNG is not apparent. The crusty appearance of the MCMB is due to a large number of small particles of the same material. The $2 \%$ carbon fiber conductive additive in the laminates is more apparent in the higher magnification images in Figure 2. 


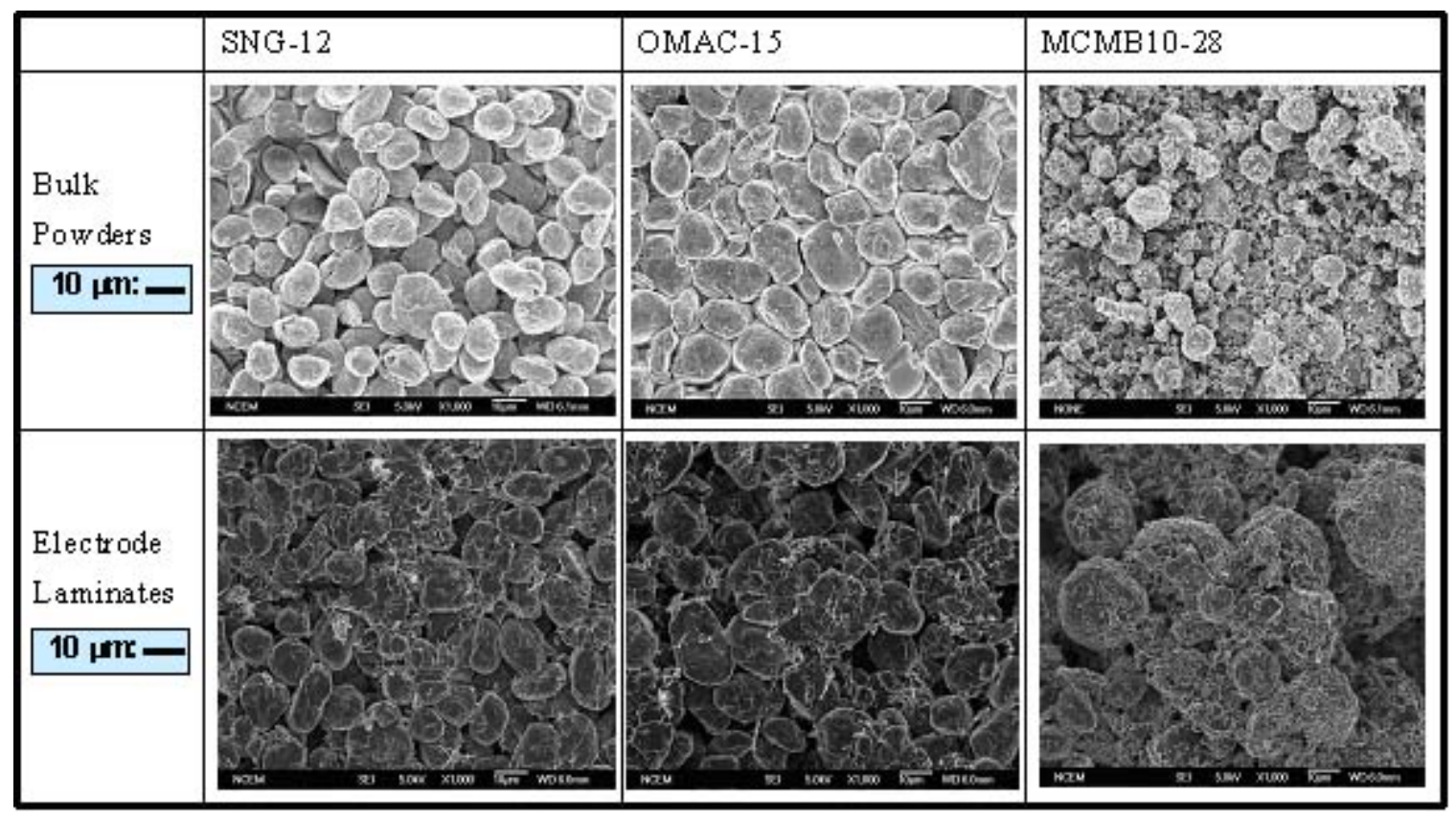

Figure 1. 1000X SEM images of the powders and Hydro Québec's laminates

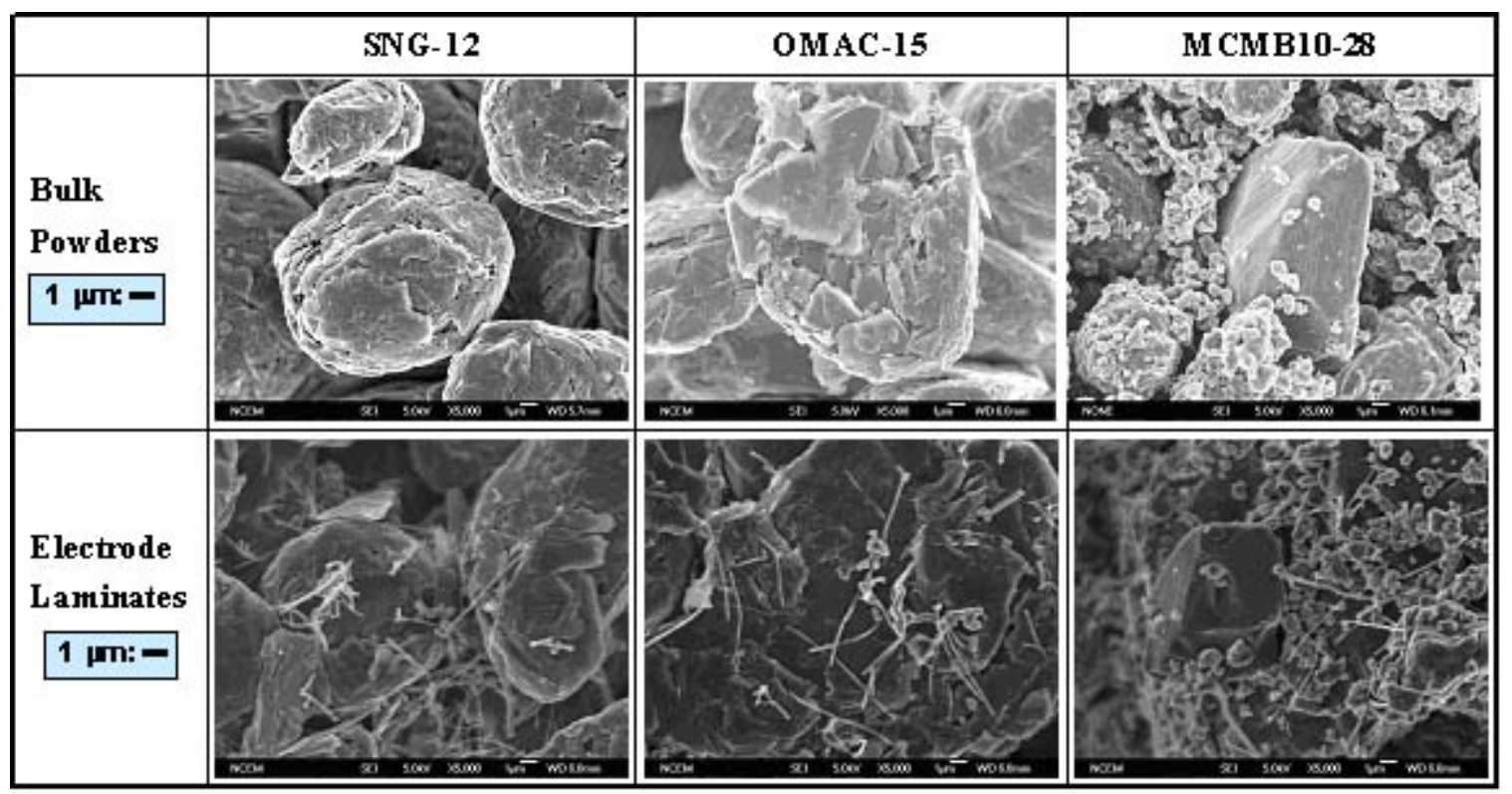

Figure 2. 5000X SEM images of the powders and Hydro Québec's laminates

The HQ laminates consist of an active layer containing the active anode material and conductive carbon fiber (Showa Denko, Japan), bound in a matrix of polyvinyldifluoride (PVdF) polymer (Kureha, Japan), coated onto a much heavier copper current collector. Properties of the laminates are listed in Table II. The thickness of the active layer is only about 1.2-1.5 particle diameters, so most of the active material particles are likely to be in contact with the current collector. The current collector weight was determined using pieces of bare collector cut from the edges of the laminates. The active layer thickness was determined by subtracting the thickness of the bare current collector from the thickness of the entire laminate, both measured with a micrometer to the nearest micron. The active material loading was determined by subtracting the weight of a $14.29 \mathrm{~mm}$ (9/16") diameter piece of the current collector from the weight of the entire electrode, and 
multiplying by the weight fraction of active material (0.93) given by HQ. Since the active layer makes up only about $10 \%$ of the electrode weight, the uncertainty of $\pm 0.2 \mathrm{mg}$ in the current collector weight leads to an uncertainty of $\pm 5-7 \%$ in the weight of active layer, which in turn results in a similar uncertainty in the active material specific capacity $(\mathrm{mAh} / \mathrm{g})$ calculated from the cycling data.

Table II. Properties of electrode laminates made by HQ

\begin{tabular}{|c|c|c|c|c|}
\hline & Property & SNG-12 & OMAC-15 & MCMB10-28 \\
\hline Activ & e layer (AL) thickness $(\mu \mathrm{m})$ & $22 \pm 3$ & $20 \pm 2$ & $40 \pm 2,18 \pm 2$ \\
\hline $\begin{array}{l}\text { Activ } \\
\text { electr }\end{array}$ & $\begin{array}{l}\text { e material loading per } \\
\text { ode, min-max (mg) }\end{array}$ & $\begin{array}{c}2.9-3.8 \\
\pm 0.2\end{array}$ & $\begin{array}{l}2.9-3.7 \\
\pm 0.2\end{array}$ & $\begin{array}{l}2.9-4.5 \\
\pm 0.2\end{array}$ \\
\hline Curre & nt Collector Weight (mg) & $23.6 \pm 0.2$ & $23.7 \pm 0.2$ & $23.7 \pm 0.2$ \\
\hline $5 \approx$ & Active material & & 93 & \\
\hline 起 & Carbon (Fiber) & & 2 & \\
\hline 包 & PVdF & & 5 & \\
\hline
\end{tabular}

Electrode laminates with similar active material loading were also prepared in this laboratory (LBNL) from the powder samples of the anode materials obtained from HQ using carbon black instead of carbon fiber, in the same proportions of active material, conductive carbon additive and PVdF binder(2).

\section{Coin cell fabrication and cycling protocol}

$14.29 \mathrm{~mm}$ (9/16") diameter anodes were punched from sheets of electrode laminate and mounted into 2325 coin cells with Celgard separators, lithium foil counter electrodes and about $60 \mathrm{mg}$ (5 drops) of $1 \mathrm{M} \mathrm{LiPF}_{6}$ in 1:2 EC:DMC solvent $(3,4)$. A current of C/24 was applied for both charge and discharge for two formation cycles followed by $\mathrm{C} / 10$ for ten cycles using a Maccor model 4200 cell cycler. Cells were held at open circuit for 30 minutes between each charge and discharge. Standard cycle limits of $1 \mathrm{~V}$ and $5 \mathrm{mV}$ were used except where noted.

The first cycle reversible and irreversible capacities of cells made with both LBNL and HQ anode laminates were measured as reported in the results section. After 10 cycles at $\mathrm{C} / 10$ were completed, rate performance of the cells was measured at currents from $\mathrm{C} / 10$ to $20 \mathrm{C}$.

\section{Capacity shift as a measure of anode performance}

The first charge (or lithiation) of a new carbon anode versus lithium requires more coulombs than does the discharge. The difference, called the irreversible capacity loss, reflects the amount of electrolyte consumed in the formation of the SEI layer. When cycling data is plotted as voltage versus capacity as in Figure 3, the first discharge limit is seen to be shifted along the capacity axis by the amount of the irreversible capacity loss. In subsequent cycling, this "capacity shift" continues to a much lesser extent. Typically the charge limit increases by a similar capacity shift, so the reversible capacity remains 
comparatively constant, which is why this is called a shift rather than a loss. This continuing shift is an undesirable trait as it indicates a continuing irreversible loss of lithium into the anode, which would decrease the reversible capacity of a "full cell" (one with a metal oxide cathode vs carbon anode).

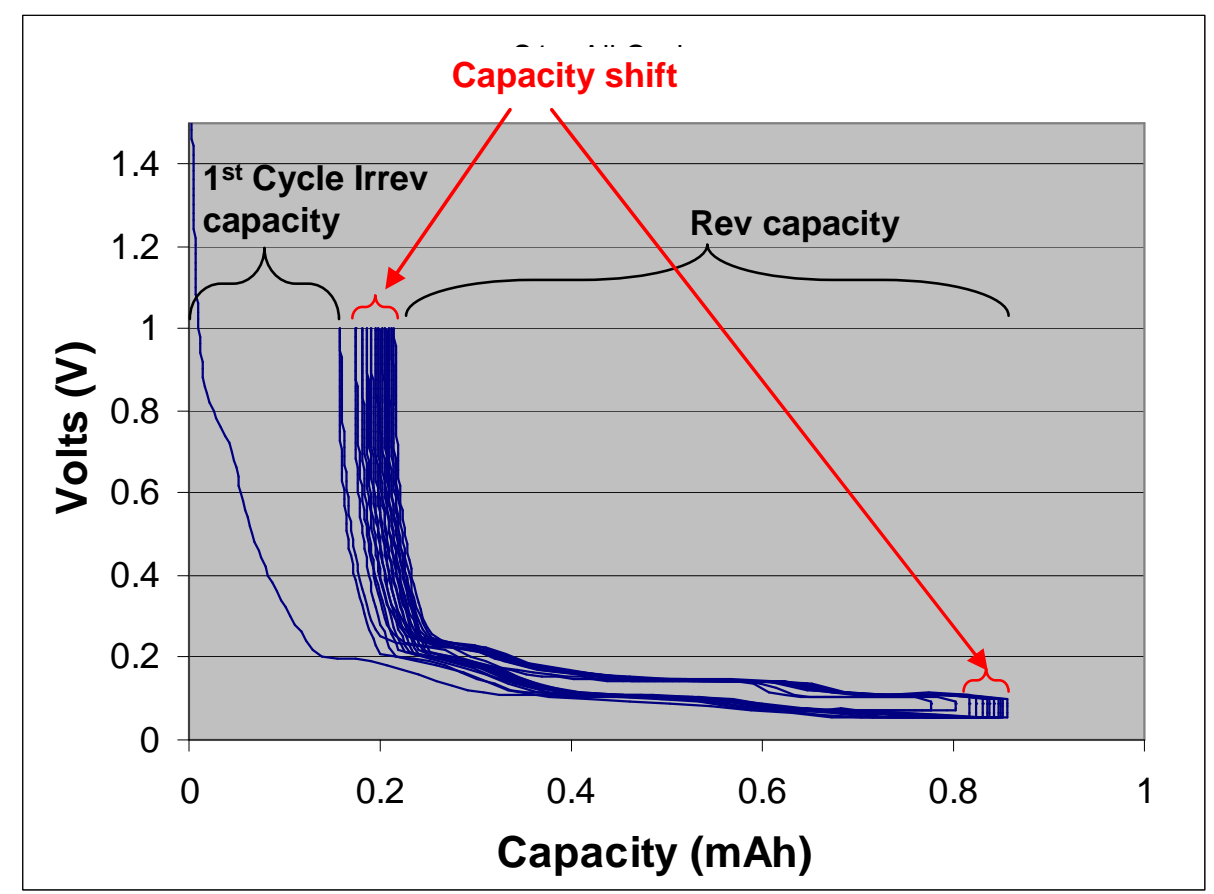

Figure 3. Plot of cycling data for an MCMB anode vs lithium showing $1^{\text {st }}$ cycle irreversible capacity, reversible capacity and the continuing capacity shift.

Finally, a study of the effect of cycle limits on cycling efficiency was done by comparing the "capacity shift" obtained with the default cycle limits, to the capacity shift observed under cycle limits more like what an anode is subjected to in a typical full cell. To get an indication of what those cycle limits might be, we constructed a hypothetical full cell charge and discharge curve from experimental lithium half-cell data: We selected this half cell cycling data for a typical anode (MCMB), and subtracted it from Li half-cell data for a typical cathode $\left(\mathrm{Li}_{1 / 3} \mathrm{Ni}_{1 / 3} \mathrm{Co}_{1 / 3} \mathrm{Mn}_{1 / 3} \mathrm{O}_{2}\right)$, thus obtaining hypothetical charge and discharge curves for the corresponding full cell. These simulated full cell charge and discharge curves and the half cell data used to derive them are plotted in Figure 4. The cathode half-cell data were modified by scaling the capacity values to reflect the greater capacity of the anode in a well-designed commercial cell. The greater capacity of the anode consists of about $10 \%$ greater reversible capacity to avoid plating of lithium on the anode near the end of cell charge, and another 5\% due to the larger size of the anode designed to reduce chance of misalignment of the electrodes during cell assembly.

In Figure 4, construction lines are drawn from the full cell data at typical full cell charge and discharge voltage limits to the corresponding points on the anode half-cell curves. These points on the anode curves are quite different from the standard cycle limits used to evaluate anodes in lithium half cells $(1 \mathrm{~V}$ and $5 \mathrm{mV})$. Therefore, we decided to compare anode performance obtained with the standard cycle limits to the performance obtained at cycle limits closer to what the anode is subjected to in a full cell. The discharge limits chosen were 0.8 and $0.4 \mathrm{~V}$. As the charge limit occurs in a region of 
nearly constant voltage, use of a voltage limit would be unreliable. Therefore, we chose capacity limits of about 75 and $90 \%$ of full charge. These are capacity (mAh) limits calculated from data obtained with cells incorporating carbon electrodes cut from the same laminate sheets cycled to standard limits, and include correction for electrode weight.

We evaluated the effect of modified cycle limits on anode performance by measuring the per-cycle "fractional capacity shift" (FCS, the capacity shift divided by reversible capacity). Our other performance monitors (first cycle reversible capacity and irreversible capacity) are not useful for this because they are obviously and spuriously affected by changes the cycle limits. For example, charging to $85 \%$ of the reversible capacity obtained with normal cycle limits reduces the reversible capacity by $15 \%$ (a tautology). The reduced charge limit reduces the time spent at the low voltages where the SEI layer is formed, so the irreversible capacity loss will decrease, though not by a precisely predictable amount. This could lead to formation of less SEI layer which could, however, conceivably lead to a greater continuing capacity shift, a significant change in performance we would capture directly by measuring the FCS. Reducing the discharge limit to $0.4 \mathrm{~V}$ will also obviously decrease the reversible capacity by an amount corresponding to the change of the discharge limit's position along the capacity axis (see Figure 3). The irreversible capacity loss will obviously increase by that same amount. Thus we used only the FCS to measure the effect of modified cycle limits.

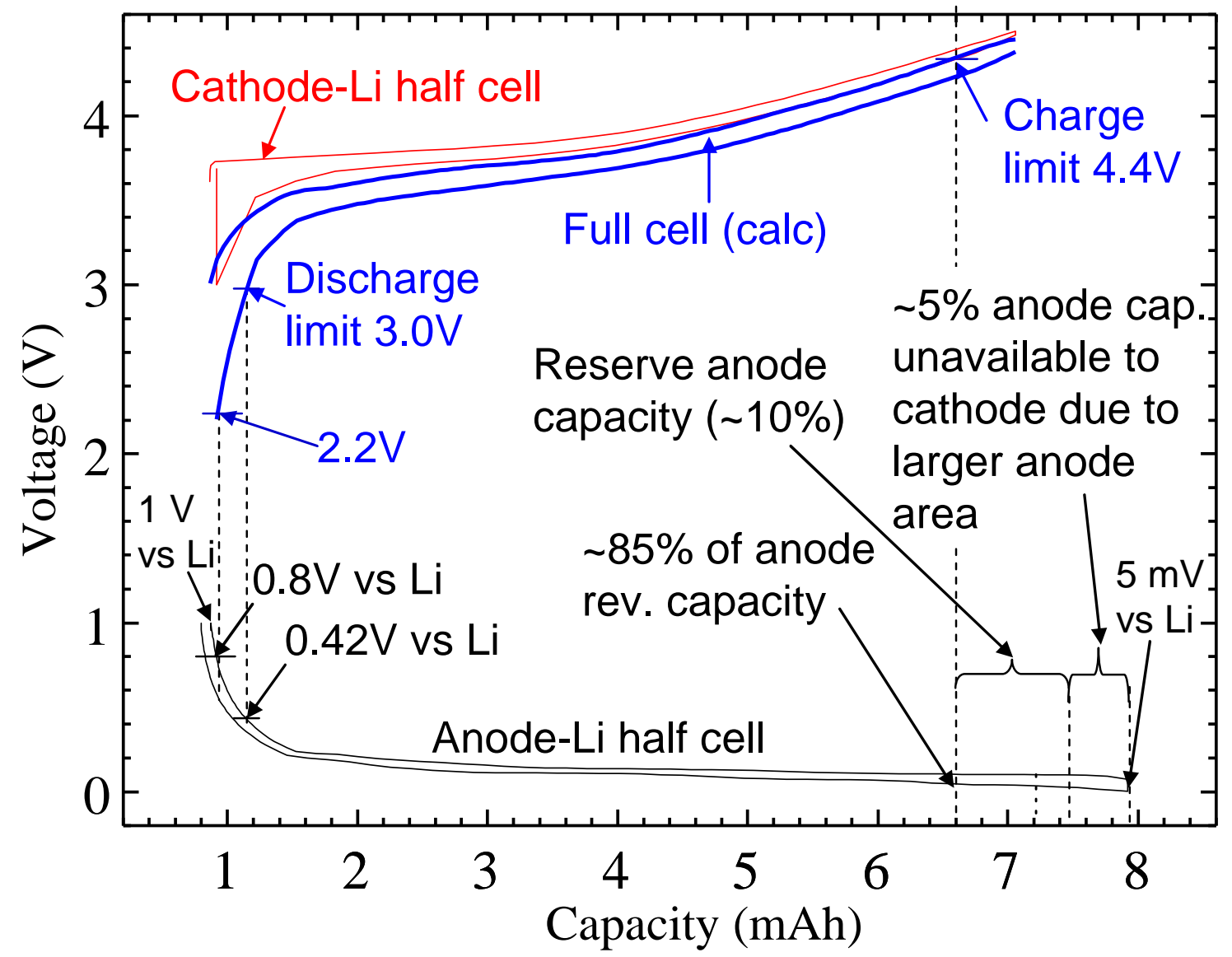

Figure 4. Calculated charge and discharge curves for a hypothetical full cell and the experimental lithium half cell data used to construct them. 


\section{Results}

First cycle performance of the anode materials under standard cycle limits ( $1 \mathrm{~V}$ to $5 \mathrm{mV}$ )

The first cycle reversible capacity and the fractional irreversible capacity (irreversible capacity divided by total capacity) of the three anode materials are given in Figure 5. The error bars represent the standard deviation of the measurements among duplicate cells. The actual uncertainties in the measurements are larger (5-7\%) due to uncertainty in the current collector weight. Though the three materials have similar reversible capacities, SNG clearly has the highest irreversible capacity loss. This is likely due to the larger specific surface area of SNG, which would require formation of more SEI layer, and the corresponding greater irreversible reduction of electrolyte.
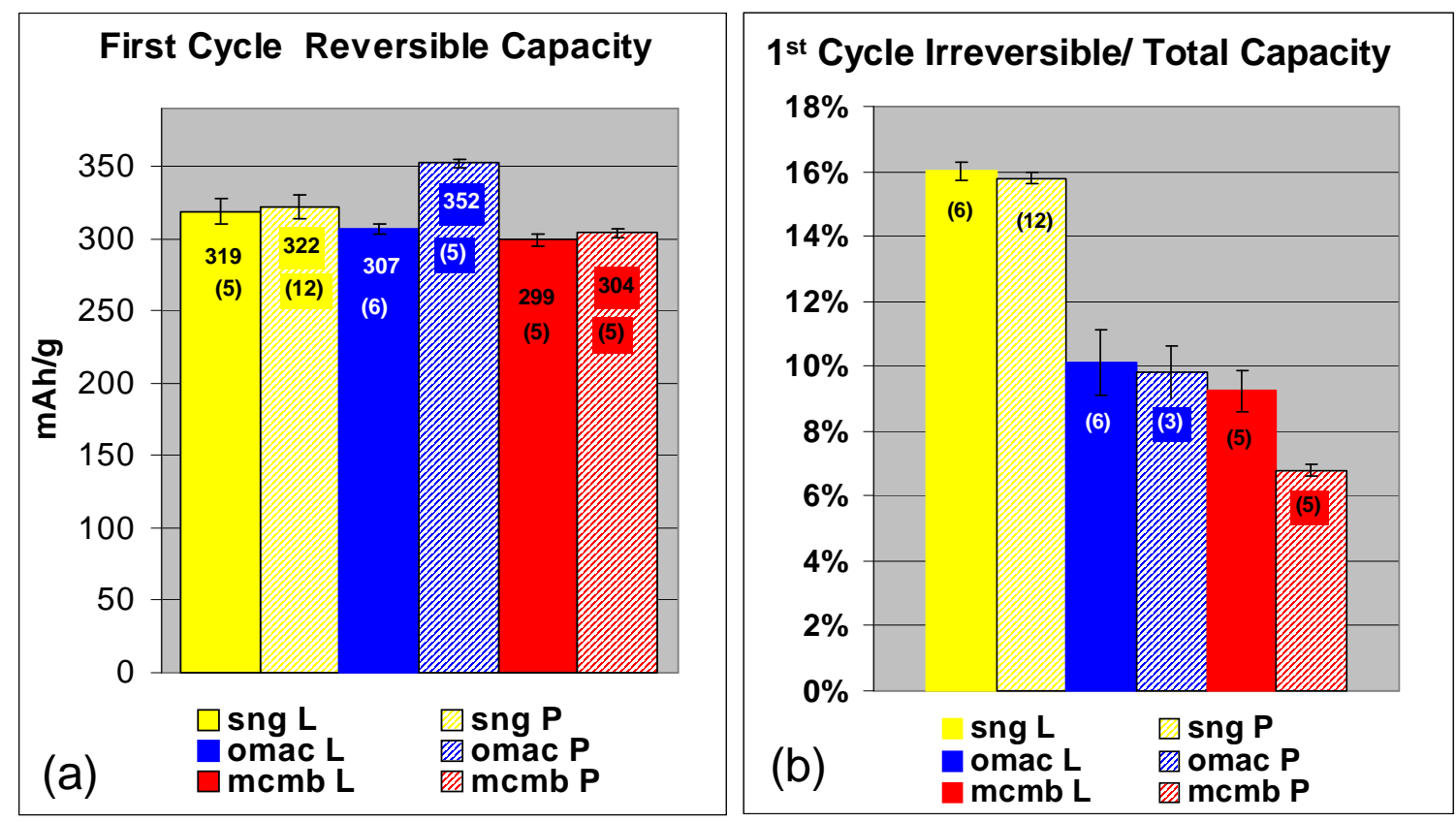

Figure 5. The first cycle reversible capacity (a) and (fractional) irreversible capacity loss (b) of the three anode materials. Value in parentheses is the number of cells cycled. L: anode laminates made at HQ; P: anode laminates made at LBNL

$\underline{\text { Rate performance of the three anode materials under standard cycle limits }}$

Three samples of each anode material (HQ laminates only) were cycled at currents to 20C. The plot of normalized capacity vs discharge rate is shown in Figure 6. The performance of OMAC and SNG were indistinguishable and only slightly better than MCMB, all three materials retaining $95 \%$ of the $\mathrm{C} / 10$ capacity with currents to $10 \mathrm{C}$. That the HQ laminates were only1.5 to 2 active material particle diameters thick contributed to this high rate performance. 


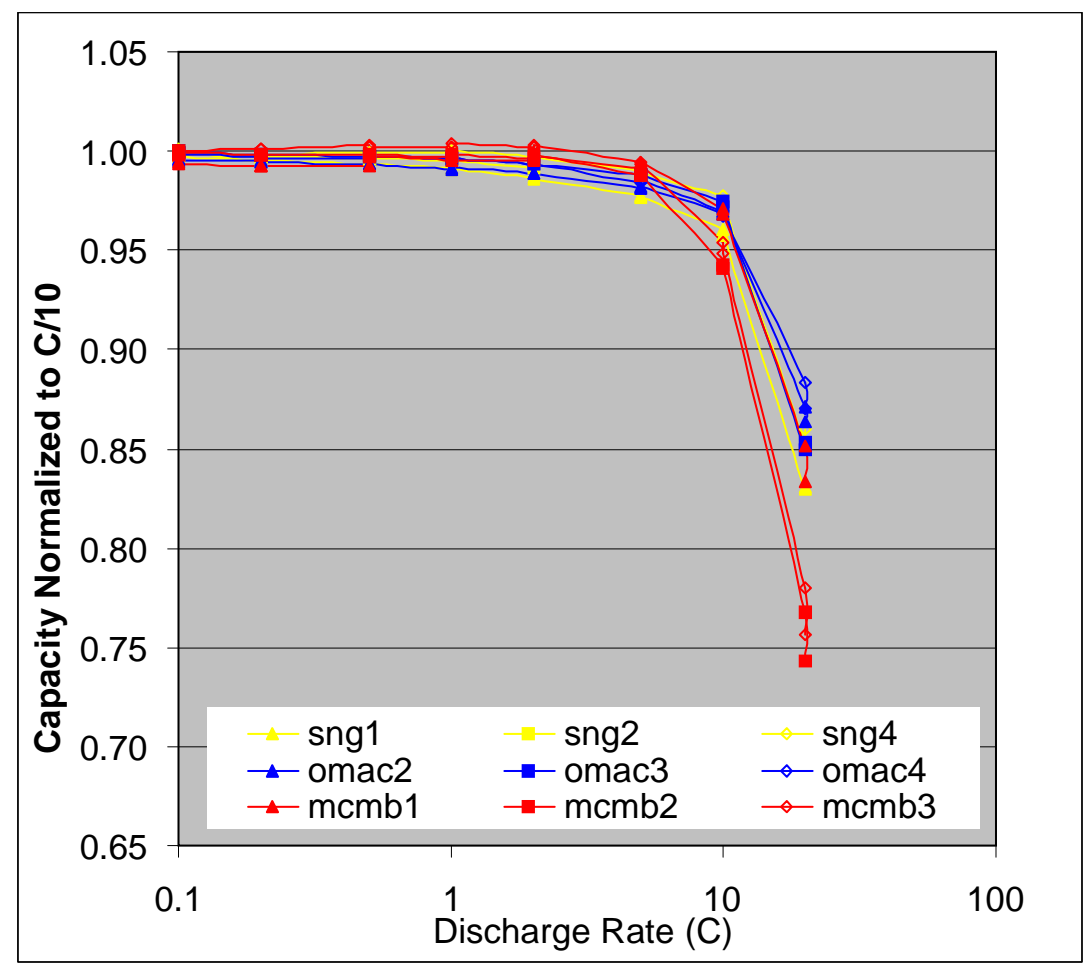

Figure 6. Rate performance of the three anode materials under standard cycle limits

\section{Capacity Shift}

In Figures 7-11 the data presented are the "fractional capacity shift" (per-cycle capacity shift divided by the reversible capacity, FCS) plotted versus the cycle number, beginning with cycle 3. The first and second cycles are formation cycles (see Experimental Section) in which the capacity shifts are much larger than for the subsequent cycles. By beginning these plots with cycle 3, we are focusing on how well the SEI layer forms and protects the cell at higher cycle numbers from continued consumption of lithium due to side reactions.

FCS Under Standard Cycle Limits. Figure 7 shows the FCS under standard cycle limits $(5 \mathrm{mV}$ to $1 \mathrm{~V})$ for the three anode materials. Three cells for each of SNG and OMAC and two cells for MCMB are shown. The capacity shift during cycling is greatest for $\mathrm{SNG}$ and least for MCMB for all cycles. 


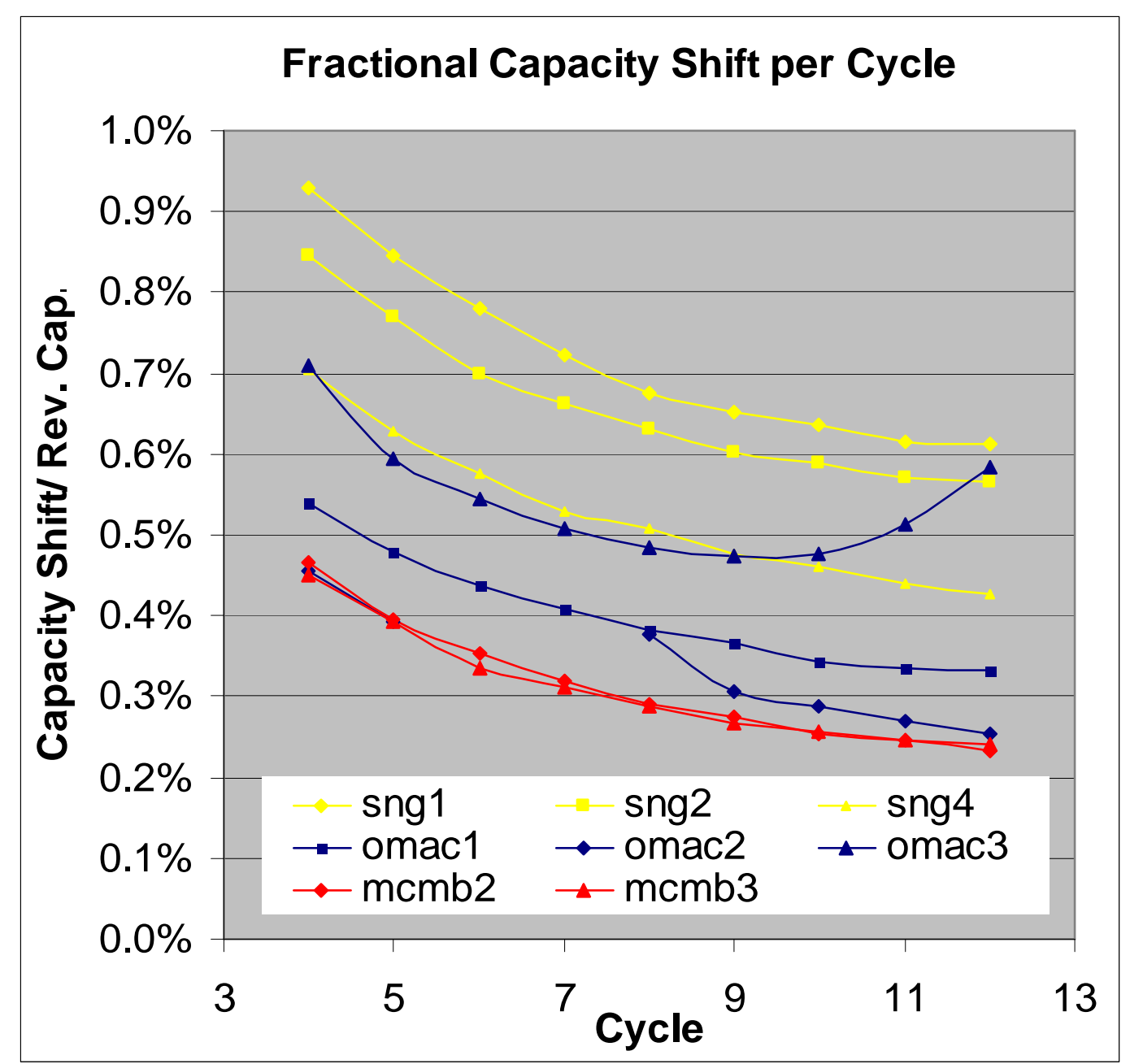

Figure 7. FCS vs cycle number for the three anode materials cycled to the standard limits

FCS Under Modified Charge Limits. For the reasons discussed in the Experimental section, we tested the effect of modified cycle limits on cell performance. One cycle limit was changed from the standard limit in a given experiment. The analysis (Figure 4) suggests that the anode is not charged in a commercial cell as far as to $5 \mathrm{mV}$ vs Li. Therefore, we cycled to reduced charge (carbon lithiation) limits of 75 and $90 \%$ of the full charge limit. This is a capacity (mAh) limit as explained in the Experimental section. Figures 8 and 9 show the FCS data for these cells. The standard cycle limit data are included for comparison. Figure $9 \mathrm{~b}$ is a plot of all of the reduced charge limit data. These data indicate that the reduced charge limit does not have a significant effect on the FCS. If only because of the greater number of experiments shown in Figure 9 (compared to Figure 7) perhaps Figure 9 shows more clearly that SNG has a greater FCS per cycle than OMAC and MCMB, while the latter two materials perform similarly by this criterion. 

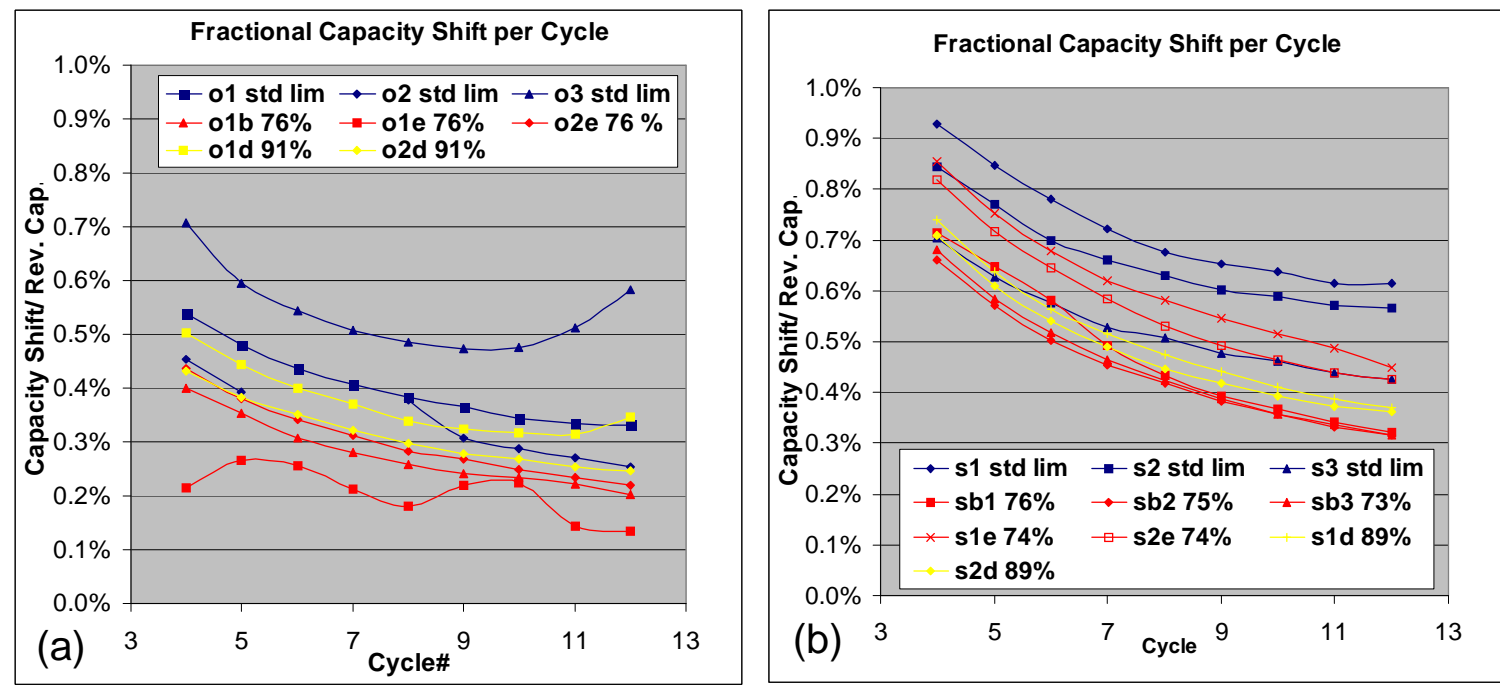

Figure 8. FCS under reduced charge limits for OMAC (a) and SNG (b).
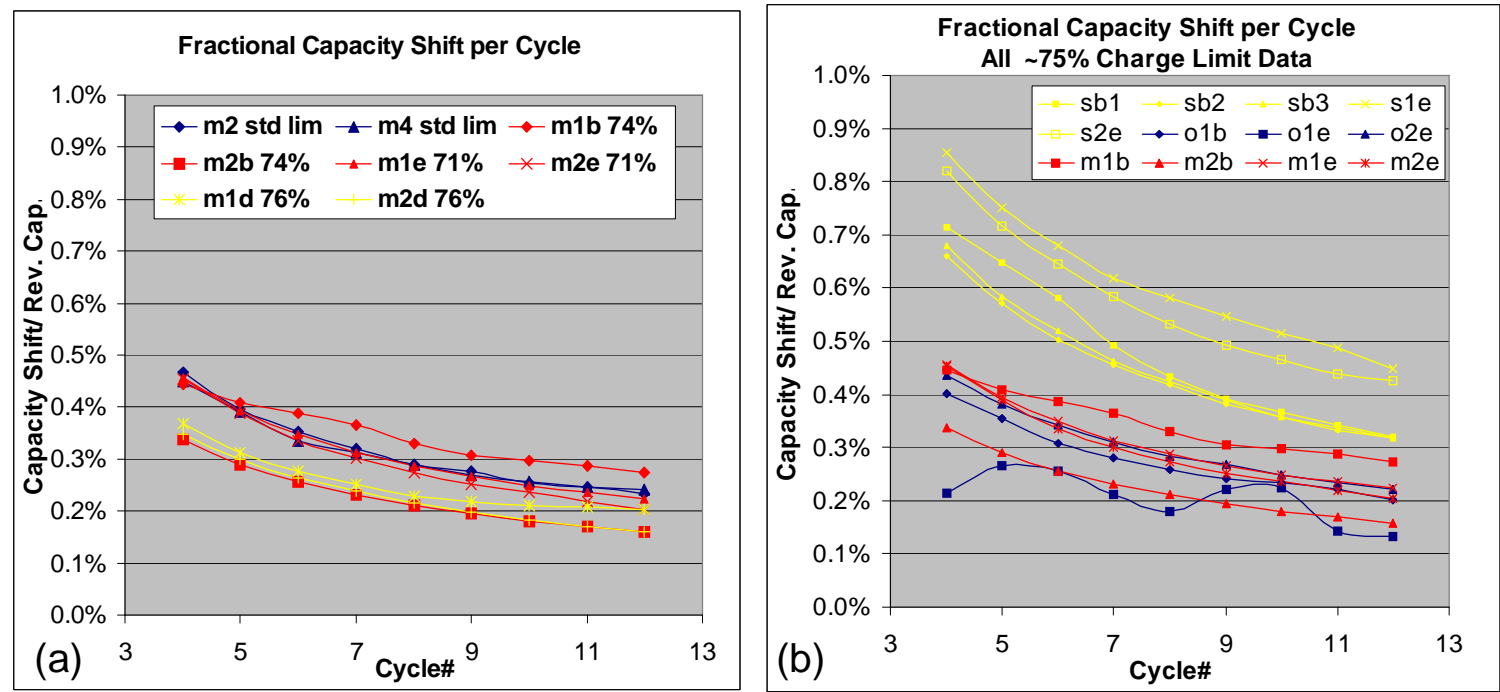

Figure 9. FCS under reduced charge limits for MCMB (a) and for all three anode materials (b)

FCS Under Modified Discharge Limits. The analysis described in the Experimental section suggests that the anode is not discharged in a commercial cell as far as to $1 \mathrm{~V}$ vs Li. Therefore, we investigated the effect of reducing the discharge limit to 0.8 and to 0.4 $\mathrm{V}$. The results are shown in Figures 10 and 11 , with $11 \mathrm{~b}$ being all of the $0.4 \mathrm{~V}$ discharge limit data in one plot. The data show that the reduced discharge limits have no significant effect on the FCS. 

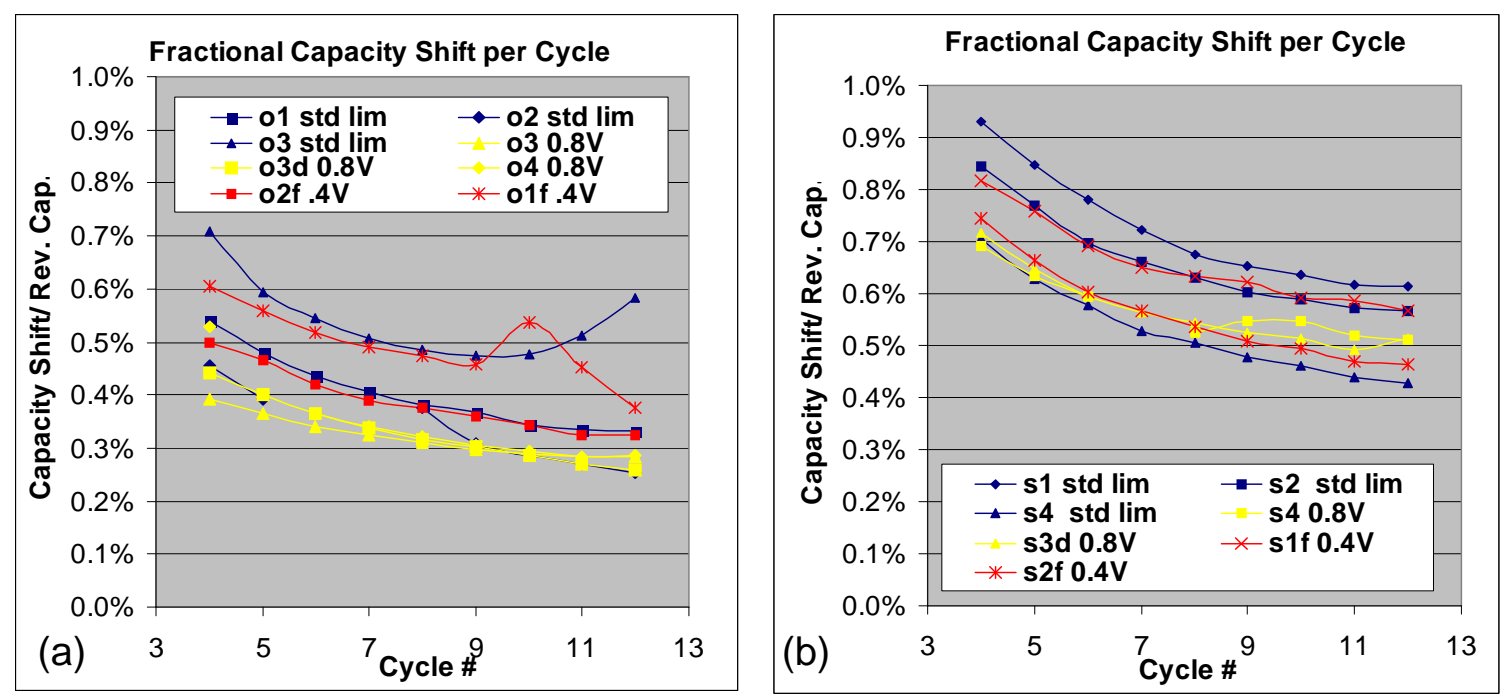

Figure 10. FCS data with reduced discharge limits for OMAC (a), and SNG (b)
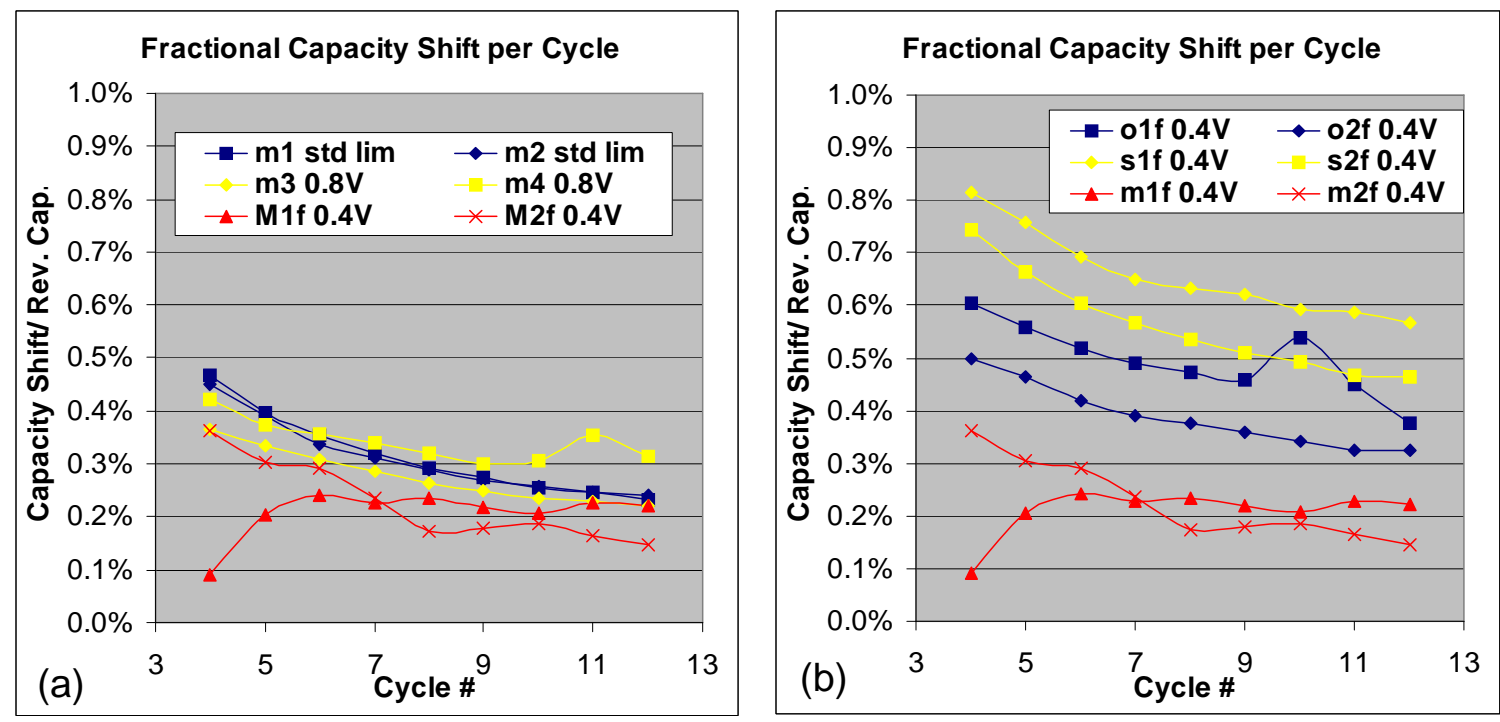

Figure 11. FCS data with reduced discharge limits for MCMB (a), and for all three anode materials (b)

\section{Conclusions}

Three carbonaceous materials have been tested as anode materials in lithium halfcells via charge-discharge cycling. The reversible capacity of OMAC was found to be higher than that of MCMB by slightly more than the measurement uncertainty of 5-7\%. The reversible capacity of SNG was found to be within that uncertainty of being equal to the capacities of both OMAC and MCMB. The irreversible component of the total capacity of SNG was found to be considerably greater than the other two anode materials. This is probably due to the reduction of electrolyte at the interface with its four-fold greater specific surface area.

The FCS of the three materials were found to follow the order of the three materials with respect to irreversible capacity $(\mathrm{SNG}>\mathrm{OMAC}>\mathrm{MCMB})$. Neither variation of the charge nor the discharge cycle limit was found to significantly affect the FCS. 


\section{Acknowledgments}

This research was funded by the Assistant Secretary for Energy Efficiency, Office of Vehicle Technologies of the U.S. Department of Energy as part of the BATT program, under contract no. DE-AC02-05CH11231

\section{References}

1. T. Takamura and R. J. Brodd, in New Carbon Based Materials for Electrochemical Energy Storage Systems, I.V. Barsukov, et al. Editors, 157-169.(C) 2006 Springer. Printed in the Netherlands.

2 Battery-grade $\mathrm{AB}$ with an average particle size of $40 \mathrm{~nm}$ and a material density of $1.95 \mathrm{~g} / \mathrm{cm} 3$ was acquired from Denka Singapore Private Limited. PVDF no. 1100 binder with a material density of $1.78 \mathrm{~g} / \mathrm{cm}$ was supplied by Kureha, Japan.

3. Coin cell parts and pneumatic press available from National Research Council Canada, Institute for Chemical Process and Environmental Technology, 1200 Montreal Rd. Building M-12, Ottowa, Ontario K1A 0R6

4. Electrolyte and solvent purchased premixed from Ferro Corporation, 7500 East Pleasant Valley Rd, Independence OH 44131, USA, and used as received. 